\title{
Cultivation of Innovative Ability of Vocational College Students Based on Class Practice Teaching
}

\author{
Xinyao Zou ${ }^{1, a^{*}}$, Shenwen Fu ${ }^{1, b}$, Yurong Liu ${ }^{1, c}$ and Nongyu Fang ${ }^{1, d}$ \\ Mechanical and electrical department, Guangdong AIB Polytechnic College, Guangzhou, China

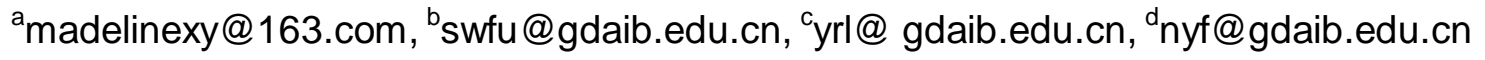

Keywords: Class practice teaching; Innovative ability; Vocational college students

\begin{abstract}
Occupation education is employment oriented, how to cultivate vocational college students' innovative ability is an important factor during building an innovative country. Practice teaching takes a very important role in cultivating vocational college students' innovation spirit and practice ability. A new practice teaching mode is presented in this paper. We introduce the characteristics of the practice teaching mode and its application effect. The results show that it's an effective mode, which can provide a useful reference for higher vocational colleges to cultivate students' innovation ability.
\end{abstract}

\section{Introduction}

Creative education is a kind of education that can cultivate creative talents, which must have strong ability of independent learning, information acquisition, observation and analysis, communication and cooperation [1]. Practice teaching is an important part of teaching activities, which can effectively cultivate vocational college students' innovative ability and improve students' comprehensive quality. Therefore, the implementation of innovative education should be based on practical teaching [2]. At present, most of China's higher vocational colleges carry out the practice teaching only for the students' practical ability and operation ability. There is no mature mode of practice teaching to cultivate vocational college students' innovation ability.

This paper focuses on the theme of cultivating students' creative ability in the course of practice teaching, and puts forward a new class practical teaching mode of "three steps", which has been applied to the teaching practice of electronic information engineering technology and applied electronic technology in Guangdong AIB Polytechnic College.

Section 2 explains the basic concepts of class practice teaching mode of three steps. Section 3 details the class practice teaching mode. Application results are given in section 4. Conclusion remarks are drawn in section 5 .

\section{Characteristics of Class Practice Teaching Mode}

The aim of the class practice teaching mode of "three steps" is to cultivate the creative ability of students in Higher Vocational Colleges. The mode has reformed the goal and function of practical teaching in higher vocational education, and the goal of practical teaching in higher vocational education has been transformed from "practical teaching skills training" to "practice teaching". In order to cultivate higher vocational college students' innovative ability, the training course is divided into three types, including cognitive training, imitative training and innovative training. As shown in table 1, according to the characteristics of different types of courses, we choose project teaching method, collaborative learning and inquiry learning separately.

Table 1. Class practice teaching mode

\begin{tabular}{ll}
\hline Class type & Teaching method \\
\hline Cognitive training & Project teaching \\
Imitative training & Collaborative learning \\
Innovative training & Inquiry learning \\
\hline
\end{tabular}


The class practice teaching mode step by step to cultivate innovative talents in higher vocational three different teaching methods, making them not only master individual skills, but also have lifelong learning and acquiring information from multiple disciplines to solve the actual problem ability. In addition, students also have a keen insight and thinking, and can follow the law of inheritance skills but also to identify what one sees and hears when they learn new knowledge and acquire new skills.

\section{Scheme of Class Practice Teaching Mode}

Class practice teaching mode cultivate students' creative thinking and innovation ability through different teaching methods to train students' individual skills, learning ability, thinking ability and the ability to obtain information to solve problems. There is a gradual and progressive relationship among the three teaching methods. In the project teaching method stage, students complete the learning task in the guidance of teachers. In collaborative learning stage, students in the semiautonomous part under the guidance of the teacher to complete the learning tasks. In inquiry learning stage, teachers give students situational problems, students independently complete the learning tasks.

Project Teaching Method for Cognitive Training Course. For higher vocational electronics professional, the main goal of cognitive training class is to enable students to understand the common electronic components, able to use common instruments, to grasp the common electronic components detection method and circuit production and maintenance of master the basic method, circuit principle and circuit design of the basic ideas and steps etc. These are the basic knowledge and basic skills of electronic innovation activities. In the practice teaching of these courses, the project teaching method is adopted.

Project teaching method is based on a constructivist teaching theory. The main features of the project teaching method are task driven, specifically, teachers design tasks, which include the content of knowledge and skills, can be one or several tasks according to the actual situation, and then start the whole process of teaching based on the tasks, students directly involved in the completion of the tasks. During the teaching process, the teacher guides the students to analyze the teaching tasks, carry out group discussions, put forward problems and try to solve them according to the results of the discussion. Project teaching method change the teacher-centered into student-centered, which greatly arouses the enthusiasm of the students, trains students to master relevant professional knowledge and skills, and cultivate the students' practice ability, put forward the question, to observe the ability to analyze and solve problems.

Cooperative Training Method for Imitation Training Course. Students have mastered the single skill through the study of cognitive training course. So the teaching aim of imitation training course is to further develop the learning ability, communication ability and team cooperation ability. Cooperative learning is a kind of teaching mode based on project oriented teaching method and task driven teaching method. Its basic feature is to realize the student-centered teaching concept, the teaching process is divided into six steps, namely: the arrangement of learning tasks, learning related knowledge, developing implementation plan, completing the task, submit task achievement, and multiple evaluation feedback, as shown in table 2.

Table 2 Cooperative training method

\begin{tabular}{|lcc|}
\hline \multicolumn{4}{|c|}{ Cooperative training method } & \\
\hline Step & task & object \\
\hline Step 1 & arrange learning tasks & stimulate students' learning motivation \\
\hline Step 2 & learn related knowledge & Information fusion classification \\
\hline Step 3 & develop implementation plan & Shared decision making \\
\hline Step 4 & complete the task & knowledge building and sharing \\
\hline Step 5 & submit task achievement & consolidation of knowledge \\
\hline Step 6 & multiple evaluation feedback & knowledge and ability promotion \\
\hline
\end{tabular}


The first step is to stimulate learning motivation by setting up the learning tasks. At this stage, teacher design task order for each task, which has specific requirements and is displayed in the network course of "online task" module. Teachers stimulate students' learning motivation through WeChat public number, QQ group, etc.

In the second stage, the teacher provides abundant teaching resources through the network curriculum platform to facilitate the students preview. Before the class, the students learn the knowledge related to the task through the network teaching platform. Then, the students integrate the learning information of individuals and groups, and feedback the questions in the question answering system. The teacher can answer questions online through the answering system, and then explain the relevant knowledge in the classroom.

In the third step, after learning the relevant knowledge points, the students are divided into the study group to discuss the exchange, brainstorming and other methods can be used to develop a reliable task to complete the program.

In the fourth step, the learning team work together to complete the task according to the proposed scheme. In the process of completing the task if students encounter problems, first of all, the team needs to find solutions. If team cannot solve, teachers can be a guide to provide ideas and information, but the specific implementation process must be completed by students. This process is a collaborative process of knowledge creation and sharing.

In the fifth step, after the completion of the task, the study team needs to fill in the task list, and submit the task list and task results. According to the specific mode of the task, the choice can be submitted through the network teaching platform, or in the classroom. In general, simple tasks submitted directly to the network teaching platform, complex tasks in classroom demonstration. Teachers provide a way to share and learn from each other, so as to achieve the goal of integrating knowledge and further consolidating and deepening the knowledge.

Finally, teachers should establish a multi evaluation system, including three aspects, such as inter group evaluation, group evaluation and teacher review. After submitting the task, study group carry out mutual evaluation. Then, teachers carry out summary comments, and further encourage students to develop in various ways based on this task.

Inquiry Learning Method for Innovative Practice Course. Inquiry learning is a kind of positive learning process, teachers create a certain situation for students, students need to find and solve problems independently. The main characteristic of inquiry learning is to emphasize the change of learning style, and to focus on cultivating students' ability to carry out the research work and the ability to solve practical problems. The basic process of inquiry learning is divided into the following five stages.

In the first stage, teachers need to design the problem situation carefully. The presentation of the problem can be an enterprise project, a case or other. First of all, the students independently analyze the problem situation, put forward their own views on the basis of the existing knowledge, and then discuss in groups, and jointly determine the issues that need to be studied.

In the second stage, the main task of students is to carefully analyze the problem, clear what information is known, what information is needed to further study to obtain, and how to obtain the unknown information. Through the implementation of this process, members of the team to refine the understanding of the issues studied, and work out a solution to the problem. Finally, the small group leader is responsible for the division of tasks according to the field of expertise.

In the third stage, the team members carry out independent learning according to the assigned tasks, collecting information, processing, and implementation. The whole process is fully completed by students, and teachers do not give any guidance.

In the fourth stage, each group demonstrated problem solving results, after the completion of each group show, teacher organizations dominated by the process of evaluation of the evaluation activities, including teacher assessment, peer assessment and self-assessment in three aspects, including learning attitude, knowledge acquisition, teamwork, works and ability raise five aspects. 
In the fifth stage, the teacher first summarizes the learning activities involved in the relevant knowledge, and then summarize the reflection of students learning activities, in order to better improve the next learning quality and efficiency.

\section{Application of Class Practice Teaching Mode}

The application of electronic technology in Guangdong AIB Polytechnic College was established in 1999. Since 2011, it has carried out the practice teaching mode of dividing class to cultivate students' innovation ability. In the past 5 years, the reform has made some achievements in the cultivation of students' innovation ability, mainly reflected in the following aspects: (1) The students got the utility model patent of 10, the declaration of invention patents of 1. (2) The students won the award for the invention and innovation of the seventh Beijing invention and innovation contest. (3) Students published 3 scientific papers. (4) Students obtained the key projects of Guangdong Provincial College Students' scientific and technological innovation. (5) In terms of competition, both quantity and quality have been greatly improved, in terms of quantity, from the previous 3 awards increased to 34; in quality, from the provincial award to the national award.

\section{Conclusion}

In order to cultivate higher vocational college students' innovative ability, this paper explores a class practice teaching mode, which can cultivate higher vocational students' innovation ability in the second class practice teaching process. This mode was applied in major of electronic engineering of Guangdong AIB Polytechnic College for five years, the practice results show that this model is feasible in higher vocational training the innovation ability of students. The cultivation of innovation ability is a complex project, in addition to the practice teaching mode, there are many problems need further study and discussion.

\section{Acknowledgements}

Supported by Higher Vocational Education Reform Project of Guangdong, China under grant No.201401155. Teaching reform project of Guangdong Skills Competition Teaching Steering Committee of Guangdong, China under grant No. 201509002.

\section{References}

[1] Wang Jie, the plight and breakthrough of students' innovation ability training [J]. Teaching and management, 2013, (1): 66-68.

[2] Niu Qingwei, Hu Wei, et al. Research and practice of practical teaching system for cultivating students' innovative ability [J]. Chinese university teaching, 2011 (10): 70-73. 